\title{
Facile Fabrication of Porous Hydroxyapatite Monoliths: Their Enhanced Bioactivity and Adsorption Capability for Heavy Metal Ions
}

\section{Xiao-Hui Guo*, Wa-Nv Wang, Meng-Jiao Wang, Chao-Chao Mao, Ji Zhang, Fan-Li Meng and Wei-Wei Xu}

Key Lab of Synthetic and Natural Functional Molecule Chemistry of Ministry of Education, and the College of Chemistry \& Materials Science, Northwest University, Xi'an 710069, P. R. China

\begin{abstract}
Porous Hydroxyapatite (HAP) monoliths with hierarchically adjustable surface textures have been successfully prepared by pouring the HAP precursors into the gap among the preorganized poly (styrene-methyl methacrylateacrylic acid) (P (St-MMA-AA)) colloidal sphere arrays and followed by a simple calcinations processes. Herein, the as-obtained HAP monoliths can undergo distinct morphologies evolution by gradually altering the features of polymeric colloidal spheres. Typically, when only $800 \mu \mathrm{l}$ colloidal spheres were used as templates, a kind of specific HAP monolith with hierarchical porous structural feature could be produced. They display higher specific surface area of $\sim 49.7 \mathrm{~m}^{2} . \mathrm{g}$ ${ }^{1}$, in which microporous channel was penetrated into the macroporous framework. Furthermore, we performed and evaluated the bioactivity for the prepared HAP monoliths in simulated body fluid (SBF) conditions, indicating the greatly enhanced in vitro bioactivity of the HAP monoliths. This should be attributed to the hierarchically porous features of HAP monoliths. More interestingly, HAP monoliths with specific porous can possess specific capability for removing toxic heavy metal ions such as $\mathrm{Pb}^{2+}$ and $\mathrm{Cd}^{2+}$ in aqueous solution. Therefore, it was indicated that the obtained HAP monoliths can be employed as a highly effective adsorbent for the removal of pollutants in wastewater treatment.
\end{abstract}

Keywords: HAP; Morphology; Porous; Monolith; Bioactivity

\section{Introduction}

Hydroxyapatite (HAP), a major component of the hard tissues in bones and teeth of the human body, has been popularly applied as artificial bone substitutes due to its adequate mechanical properties and the analogical composition to bone species [1-3]. Additionally, HAP exhibits good biocompatibility, bioactivity, osteoconductive, nontoxic, noninflammatory properties, and particular adsorption capability for various metal ions, so it can be extensively applied in such as ion exchange, drug delivery and the treatments of contaminated water aspects [4-9].

In recent years, many efforts have been made for preparation of the morphology-controllable HAP nanomaterials. Moreover, HAP nanocrystals with various morphologies, such as nanotube, [10] nanofiber/microbelt, [9] nanorod, [8,13] nanosheet, [15-17] thin-films, [14] and flower-like aggregates,[11-12] could be obtained via different reaction approaches. However, its potentials are largely dependent upon the particle size, shape, dimensions anisotropy, and dimensional structure features of HAP, which are of critical importance for satisfy its practicality [18]. Among these distinct morphologies, thin films (including monoliths), have attracted increasing attention due to their broad application scope that ranged from medical technologies to solar cell manufacture.

It is interesting to point out that the monoliths with plentiful adjustable three-dimensional surface textures hold greatly promising in chemical sensors, bone substitute materials, fuel cell devices, and other nano-devices. Specially, the bioactivity of bone substitute materials is highly concerned not only with their chemical composition, but also with their structural properties, such as pore size, and surface textures. The appropriate porosity allows the ingrowths of the bone tissue to preferably contact with the living bones $[19,20]$. The ideal porous structures of bone substitute materials should consist of mesoporous and macroporous features, in which mesopores can promote cell adhesion and adsorption of biological metabolites,[21] and macropores can empower tissue ingrowths and deliver essential nutrient to the center of the regenerated tissue [22-24]. Thus, synthesis of hierarchically porous structured bone substitute materials, will certainly benefit for the tissue engineering.

It is well known that the materials with hierarchical porosity have many advantages due to their higher surface area and facilitation of substance transportation $[25,26]$. Crystallization of HAP monoliths with multiple porous structure is very essential for practical applications in biomedicine, catalyst support and sewage treatment fields. In this regard, different synthetic approaches have been exploited for the fabrication of well-defined inorganic monolith nanostructures, including pulsed laser deposition, [27] sol-gel processing [28] and spin-coating [29]. However, most of these techniques involved multiple steps and require expensive instruments, thus, the simple and adaptable synthetic methods are strongly demanded. Recently, nanostructural monolith materials have been obtained via using substrates [30-31] or colloidal spheres $[29,32]$ as templates. A recent study by Kimura et al. [29] showed hierarchically porous titania monoliths were fabricated using a tri-block copolymer $\left(\mathrm{F}_{127}\right)$ and polystyrene (PS) beads as dualtemplates, it has been found that both $\mathrm{F}_{127}$ and PS show a considerable influence on the final pore size distribution. Interestingly, Qi et al. [32] proposed a novel approach to synthesize three dimensional (3D) ordered macroporous calcite single crystals via using 3D close-packed assemblies of monodisperse colloidal spheres as template. Accordingly, it has been shown that polymeric particles can be used as ideal template

${ }^{*}$ Corresponding author: Xiao-hui Guo, Key Lab of Synthetic and Natura Functional Molecule Chemistry of Ministry of Education, and the College of Chemistry \& Materials Science, Northwest University, Xi'an 710069, P. R. China, Tel: +86 29883026 04; Fax: 8629883026 04, E-mail: guoxh2009@nwu.edu.cn

Received January 10, 2012; Accepted February 23, 2012; Published February 26, 2012

Citation: Guo XH, Wang WN, Wang MJ, Mao CC, Zhang J, et al. (2012) Facile Fabrication of Porous Hydroxyapatite Monoliths: Their Enhanced Bioactivity and Adsorption Capability for Heavy Metal Ions. J Nanomedic Nanotechnol 3:130. doi:10.4172/2157-7439.1000130

Copyright: ( 2012 Guo XH, et al. This is an open-access article distributed under the terms of the Creative Commons Attribution License, which permits unrestricted use, distribution, and reproduction in any medium, provided the original author and source are credited. 
Citation: Guo XH, Wang WN, Wang MJ, Mao CC, Zhang J, et al. (2012) Facile Fabrication of Porous Hydroxyapatite Monoliths: Their Enhanced Bioactivity and Adsorption Capability for Heavy Metal lons. J Nanomedic Nanotechnol 3:130. doi:10.4172/2157-7439.1000130

for the synthesis of numerous porous film materials under mild conditions. However, to the best of our knowledge, the study on the synthesis of HAP monoliths with hierarchically porous structures using a facile soft-template casting method have been rarely reported so far. Colloidal crystals that was resulted from 3D close-packed assemblies of monodisperse colloidal polymeric microspheres, have been widely used as sacrificial templates to fabricate $3 \mathrm{D}$ ordered porous materials, in which the pore size and its distribution of the multiple pore channels can be well controlled.

Herein (Scheme 1), we report a simple two-step synthetic strategy to fabricate hydroxyapatite monoliths with hierarchical surface textures: 1) deposition of colloidal polymeric spheres onto smooth cellulose acetate filter membrane; 2) infiltration of the freshly prepared HAP precursor into the gap of polymeric colloidal arrays. Notably, mesoporosity was interpenetrated into the macroporous channel structures. Thus, by altering the volume of the polymeric microsphere, HAP monoliths with distinct surface textures were generated. Furthermore, we performed and evaluated the in vitro bioactivity of HAP monoliths in simulated body fluid (SBF) solution, which indicated that the obtained porous HAP samples can possess apparently improved in vitro bioactivity. It was demonstrated that the HAP monoliths behave powerful capability of removing the toxic heavy metal ions like $\mathrm{Pb}^{2+}$.

\section{Experimental Section}

\section{Synthesis of polymeric colloidal spheres}

Monodisperse poly (styrene- methyl methacrylate- acrylic acid) P (St-MMA-AA) colloidal spheres were synthesized according to the previous literature [33]. Briefly, $\left(\mathrm{NH}_{4}\right)_{2} \mathrm{~S}_{2} \mathrm{O}_{8}(0.4 \mathrm{~g})$ and $\mathrm{NH}_{4} \mathrm{HCO}_{3}$ $(0.8 \mathrm{~g})$ were dissolved in aqueous solution $(120 \mathrm{ml})$ in a beaker, and $22.5 \mathrm{ml}$ styrene (St), $1.25 \mathrm{ml}$ methyl methacrylate (MMA), and $1.25 \mathrm{ml}$ acrylic acid (AA) monomer were mixed in another breaker, and then place the above two homogeneous solution into a $250 \mathrm{ml}$ flask. After that, the mixture was stirred at $70{ }^{\circ} \mathrm{C}$ in argon atmosphere for $5 \mathrm{~h}$ to obtain homogeneous latex with particle diameter of $\sim 380 \mathrm{~nm}$. When changing the volume ratios of monomer species to $85: 5: 10(\mathrm{v} / \mathrm{v} / \mathrm{v})$, the diameter of P (St-MMA-AA) colloidal particles was measured to be $\sim 170 \mathrm{~nm}$.

\section{Synthesis of porous HAP monoliths}

Colloidal polymeric spheres template were assembled on a cellulose

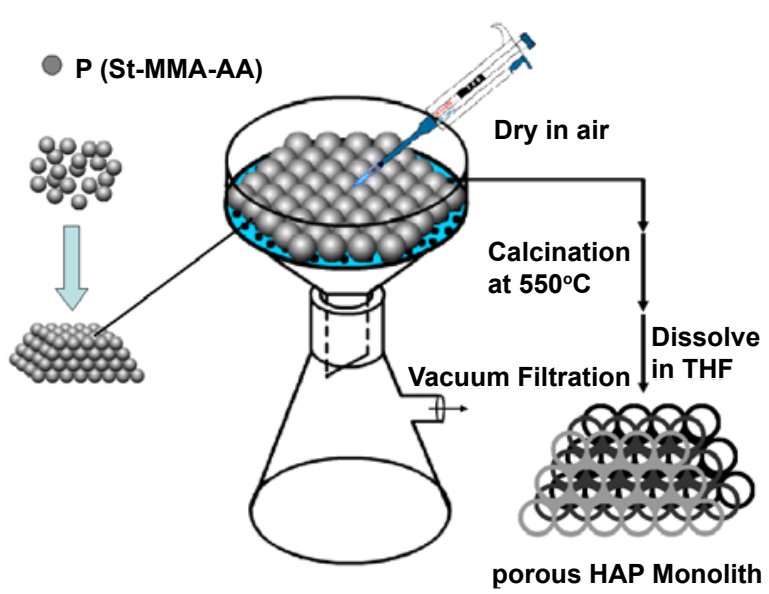

Scheme 1: The fabrication of hierarchically porous HAP monoliths by using $P$ (St-MMA-AA) polymeric microsphere arrays as template. acetate membrane, which was placed on a Büchner funnel. Then, 400 $\mu \mathrm{l}$ of the as-prepared colloidal solution was spread onto the membrane, with subsequent drying at room temperature. Afterwards, desired amount of $\mathrm{Ca}\left(\mathrm{NO}_{3}\right)_{2} \cdot 4 \mathrm{H}_{2} \mathrm{O}$ and $\left(\mathrm{NH}_{4}\right)_{2} \mathrm{HPO}_{4}$ (molar ratio of $\mathrm{Ca} / \mathrm{P}=$ $5 / 3$ ) were added into ethylene glycol $(40 \mathrm{ml})$ and nonionic water (NIW) $(20 \mathrm{ml})$ mixture solutions under vigorous magnetic stirring, adjusting $\mathrm{pH}$ to 10 by using $\mathrm{NaOH}(2 \mathrm{M})$ solution, thus a translucent solution formed immediately, indicating that the formation of precursor granules. Then, the freshly prepared solution was added drop-wise to the cellulose acetate membrane containing colloidal P (St-MMA-AA) template. Thenceforth, the obtained HAP samples were dried in air and then heated at $550{ }^{\circ} \mathrm{C}$ oven for $5 \mathrm{~h}$, afterwards; further immerse them into tetrahydrofuran(THF) solution for $6 \mathrm{~h}$ to ensure complete removal of the organic species (detailed see scheme 1).

\section{Characterization}

The samples were characterized by powder X-ray diffraction (XRD) patterns, recorded on a Bruker AXS-D8 powder diffractometer with $\mathrm{Cu}-\mathrm{Ka}(\lambda=0.15405 \mathrm{~nm})$ radiation. Films morphologies were observed by using a FEI Quanta-400 FEG scanning electron microscope (FESEM) with accelerating voltage of $20 \mathrm{KV}$. Thermogravimetry analysis (TGA) was carried out on a Diamond TG/DTA thermal analysis (Entzsch-Sta 449) with a heating rate of $10^{\circ} \mathrm{C} / \mathrm{min}$ at nitrogen atmosphere. The concentrations of phosphorus and calcium in SBF were determined using inductively coupled plasma optical emission spectroscopy (ICP-OES, Optima 5300DV, Perkin-Elmer). All measurements were performed at room temperature. Nitrogen sorption isotherms were measured at $77 \mathrm{~K}$ with a Micromeritcs Tristar 3000 analyzer (USA). Before measurements, the samples were degassed in a vacuum at $180^{\circ} \mathrm{C}$ for at least $6 \mathrm{~h}$. The Brunauer-Emmett-Teller (BET) method was utilized to calculate the specific surface area $\left(S_{\mathrm{BET}}\right)$ using adsorption data in a relative pressure range from 0.18 to 0.35 . By using the Barrett-Joyner-Halenda (BJH) model, the pore volume and pore size distributions were derived from the adsorption branches of isotherms, and the total pore volumes $(V t)$ were estimated from the adsorbed amount at a relative pressure $P / P_{0}$ of 0.992 .

\section{Evaluation the Bioactivity of HAP in SBF}

The in vitro bioactivity was evaluated by soaking HAP monoliths in SBF solution as described by kokubo [34]. The SBF was prepared by dissolving $\mathrm{NaCl}, \mathrm{NaHCO}_{3}, \mathrm{KCl}, \mathrm{K}_{2} \mathrm{HPO}_{4} \cdot 3 \mathrm{H}_{2} \mathrm{O}, \mathrm{MgCl}_{2} \cdot 6 \mathrm{H}_{2} \mathrm{O}$, $\mathrm{CaCl}_{2}, \mathrm{Na}_{2} \mathrm{SO}_{4}$ and $\left(\mathrm{CH}_{2} \mathrm{OH}\right)_{3} \mathrm{CNH}_{2}$ into deionized water step by step, with a molar composition of $142.0 / 5.0 / 2.5 / 1.5 / 147.8 / 4.2 / 1.0 / 0.5$ for $\mathrm{Na}^{+} / \mathrm{K}^{+} / \mathrm{Ca}^{2+} / \mathrm{Mg}^{2+} / \mathrm{Cl}^{-} / \mathrm{HCO}_{3}{ }^{-} / \mathrm{HPO}_{4}{ }^{2-} / \mathrm{SO}_{4}{ }^{2-}$, and buffering it at $\mathrm{pH} 7.40$ with $1 \mathrm{M}$ hydrochloric acid. Then, $0.03 \mathrm{~g}$ HAP sample was added into $50 \mathrm{ml} \mathrm{SBF}$ at $37^{\circ} \mathrm{C}$. After different immersion intervals, the samples were separated from the SBF solution, measure the residual ions concentration change in SBF at different intervals. The concentrations of phosphorus and calcium in SBF were determined by using inductively coupled plasma optical emission spectroscopy.

\section{Heavy Metal ions Adsorption Measurement}

Solutions containing $\mathrm{Pb}^{2+}$ or $\mathrm{Cd}^{2+}$ ions were prepared using $\mathrm{Pb}\left(\mathrm{NO}_{3}\right)_{2}$ and $\mathrm{Cd}\left(\mathrm{NO}_{3}\right)_{2} \cdot 4 \mathrm{H}_{2} \mathrm{O}$ as the source of $\mathrm{Pb}^{2+}$ and $\mathrm{Cd}^{2+}$, the concentrations of $\mathrm{Pb}^{2+}$ and $\mathrm{Cd}^{2+}$ are $200 \mathrm{mg} / \mathrm{l}$, respectively. Then $0.015 \mathrm{~g}$ HAP samples were added into $25 \mathrm{ml}$ the above solution under magnetic stirring interaction. The whole adsorption experiment was performed at room temperature, after different immersion intervals, solid and liquid were separated and the concentrations of metal ions remained in the solution were measured by using inductively coupled plasma 
Citation: Guo XH, Wang WN, Wang MJ, Mao CC, Zhang J, et al. (2012) Facile Fabrication of Porous Hydroxyapatite Monoliths: Their Enhanced Bioactivity and Adsorption Capability for Heavy Metal lons. J Nanomedic Nanotechnol 3:130. doi:10.4172/2157-7439.1000130

atomic emission spectroscopy (ICP-AES) to obtain the adsorption isotherm.

\section{Results and Discussion}

\section{Morphology and structure analysis for HAP monoliths}

Colloidal crystals were generally 3D close-packed polymeric spheres with well-defined array structures, which have been widely used as templates to fabricate three-dimensional ordered porous materials. Uniform P (St-MMA-AA) colloidal spheres with different diameters were prepared by using the emulsion polymerization method. HAP/ polymeric composites were formed via casting HAP precursor into the pre-formed arrays of the colloidal sphere; the volume ratio of the colloidal solution/HAP precursor is fixed at $2 / 5$. After the template was removed by sequential calcination and dissolution treatment, the product was characterized by powder XRD technique. Figure 1 shows the XRD pattern of the as-synthesized HAP sample using 170 nm P (St-MMA-AA) colloidal spheres as template, the sample can easily be indexed to pure hexagonal phase HAP according to standard JCPDS card no.09-0432, as shown in Figure 1. The presence of broad diffraction peaks is ascribed to the defective poorly crystalline nature of the formed HAP. Specially, it was found that the obtained HAP samples displayed higher diffraction peak intensity along (002) and (211) crystal facets, indicating that the preferential growth of the HAP along (002) and (211) growth directions [19].

HAP crystals with distinct morphologies were obtained by altering the volume of the colloidal solution. Figure 2 presents the SEM image of the as-made HAP monoliths using P (St-MMA-AA) (ca. $170 \mathrm{~nm}$ in diameter) colloidal array as soft-template. If only $400 \mu \mathrm{l}$ colloidal sphere was carefully poured into the cellulose acetate membrane, cavernous HAP monoliths containing microporous structure were generated (Figure 2a), but increasing the colloidal solution volume to $800 \mu \mathrm{l}$, a kind of specific HAP monolith with porous feature can be produced, in which microporous channel was incorporated within the macroporous framework (Figure $2 b$ ). Whereas, the film shape changes dramatically when the colloidal solution volume was $2 \mathrm{ml}$, resulting in the formation of multilayer HAP monoliths with specific mesoporous feature (Figure 2c), notably, Figure $2 \mathrm{~d}$ shows a side view of the sample, which suggests that the relatively thinner peripheral region for the specific porous monolith structure with thickness of around $3 \mu \mathrm{m}$. Moreover, it is obviously found that the independently controllable synthesis of porous HAP monolith samples could be achieved via changing the volume of the colloidal solution.

More interestingly, the typical morphologies of the as-prepared HAP monoliths in the presence of P (St-MMA-AA) colloidal solution $(800 \mu \mathrm{l})$ were recorded by SEM technique, as shown in Figure 3 . It is clearly seen that both the aggregated and isolated P (St-MMA-AA) colloidal spheres derived porous structures are present in a multilayer thin-film mode, and also, it exhibits well-defined multilayered feature, as well as the interesting interlinked architecture of multiple pore channels (Figure $3 \mathrm{c}$ ).

However, some novel results can be obtained via further changing the polymeric template size. Herein, Figure 4 shows the XRD pattern of the as-prepared sample in the presence of $7.5 \mathrm{ml} \mathrm{P}$ (St-MMA-AA) (ca. $380 \mathrm{~nm}$ in diameter) colloidal crystals as template. All the diffraction peaks displayed in the XRD pattern could easily be indexed to pure hexagonal structural HAP according to JCPDS card no.09-0432, as shown in Figure 4, both the obviously improved crystallinity of HAP crystal and the presence of the stronger diffraction peak (210) facets can clearly demonstrated that HAP undergoes well-resolved morphologies

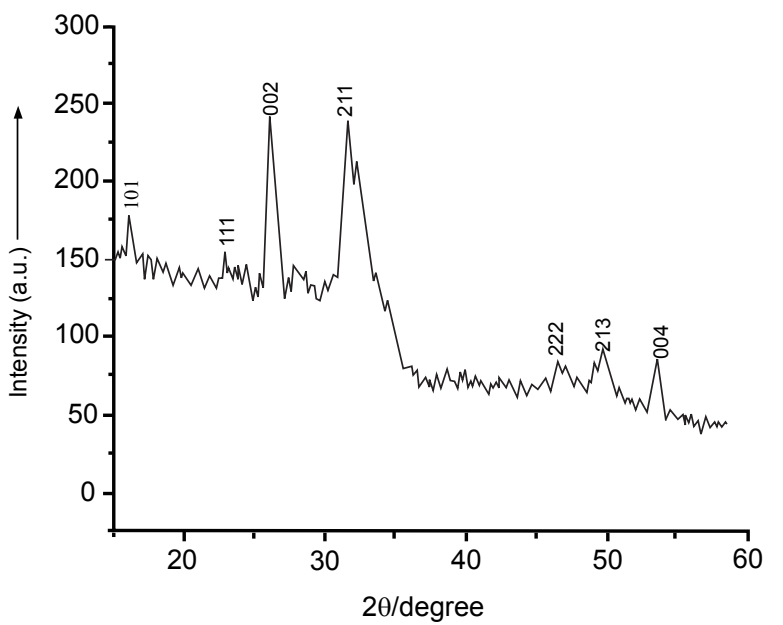

Figure 1: XRD pattern of HAP monoliths formed by using $2 \mathrm{ml} \mathrm{P}$ (St-MMA-AA) (ca. $170 \mathrm{~nm}$ in diameter) colloidal sphere arrays as template.

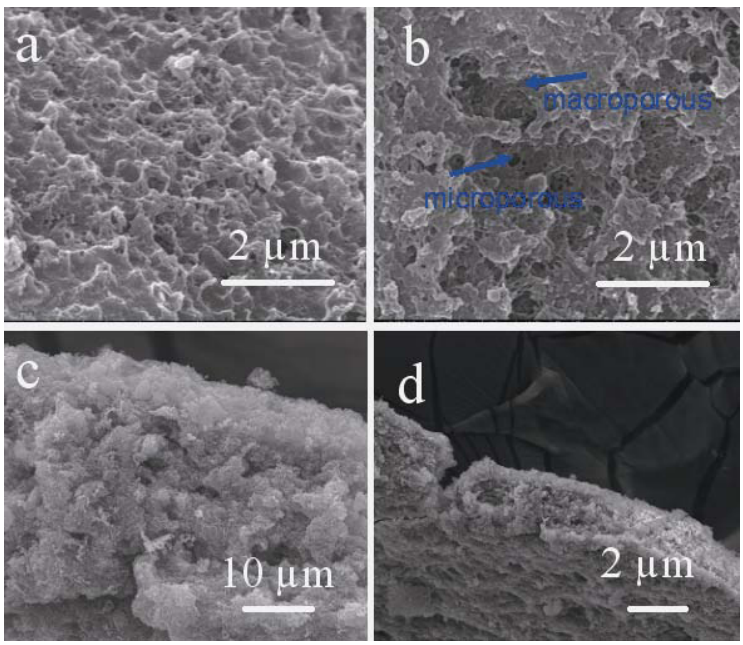

Figure 2: SEM images of HAP monoliths formed by using $170 \mathrm{~nm} P$ (St-MMAAA) colloidal sphere arrays as template with different volumes. (a) $400 \mu \mathrm{l}$; (b) $800 \mu \mathrm{l}$; (c, d) $2 \mathrm{ml}$.
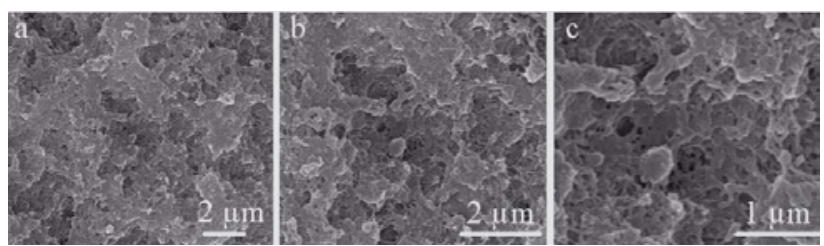

Figure 3: Typical SEM images of HAP monoliths prepared by using $800 \mu \mathrm{l}$ (St-MMA-AA) (ca. $170 \mathrm{~nm}$ in diameter) colloidal spheres as template.

change. Additionally, HAP samples with distinct morphologies were characterized by SEM, and results were shown in Figure 5.

In the meanwhile, colloidal microsphere arrays with different volumes were employed as templates; the HAP samples with distinct morphologies were obtained. When $3.5 \mathrm{ml}$ of the as-prepared colloidal solution was employed as template precursor, a stack of horizontally layered HAP monolith was generated (Figure 5a). However, the HAP 
Citation: Guo XH, Wang WN, Wang MJ, Mao CC, Zhang J, et al. (2012) Facile Fabrication of Porous Hydroxyapatite Monoliths: Their Enhanced Bioactivity and Adsorption Capability for Heavy Metal lons. J Nanomedic Nanotechnol 3:130. doi:10.4172/2157-7439.1000130

shape will changes dramatically while the volume of colloidal solution volume was increased to $5 \mathrm{ml}$, a kind of multilayer HAP monoliths with obviously macroporous and mesoporous features can be observed (Figure 5b). Notably, with the volume of the colloidal solution was increased to $7.5 \mathrm{ml}$, resulting in the formation of irregular massive-like HAP monolith with a loose porous structure (Figure $5 \mathrm{c}$ ). The results indicated that employing colloidal sphere arrays as templates could provide an effective tool for preparation of porous HAP monoliths with specific morphogenesis and surface textures.

Additionally, the BET surface area and the pore size of the HAP samples were also performed. The $\mathrm{N}_{2}$ adsorption/desorption isotherms and corresponding $\mathrm{BJH}$ pore size distribution curves of the prepared HAP samples were shown in Figure 6. The $\mathrm{N}_{2}$ adsorption/desorption isotherms for the obtained HAP monoliths via using $2 \mathrm{ml} \mathrm{P}$ (St-MMAAA) (ca. $170 \mathrm{~nm}$ in diameter) colloidal sphere arrays as template was shown in Figure 6a, the sample has a BET specific surface area of $\sim 45.2$ $\mathrm{m}^{2} \mathrm{~g}^{-1}$, and it possess two set of pore sizes: $\sim 126$ and $177 \mathrm{~nm}$ (inset in Figure 6a), respectively. However, the corresponding $\mathrm{N}_{2}$ adsorption/ desorption isotherms for the other HAP sample formed via using 7.5 $\mathrm{ml} \mathrm{P}$ (St-MMA-AA) (ca. $380 \mathrm{~nm}$ in diameter) colloidal sphere array as template displays slight difference, result was shown in Figure $6 \mathrm{~b}$. Its BET surface area was calculated to be $49.7 \mathrm{~m}^{2} \mathrm{~g}^{-1}$, its pore size distribution were measured to be 47 and $68 \mathrm{~nm}$ (inset in Figure 6b), respectively. Furthermore, the $\mathrm{N}_{2}$ absorption isotherm of HAP samples is a type IV isotherm with a typical $\mathrm{H}_{2}$ hysteresis loop.

The FT-IR spectra of the as-prepared HAP monoliths before and after removing polymeric colloidal template were shown in Figure 7. Herein, Figure 7a shows the FT-IR result of HAP/polymeric composite, the characteristic band centered at $1490 \mathrm{~cm}^{-1}$ can be assigned to the

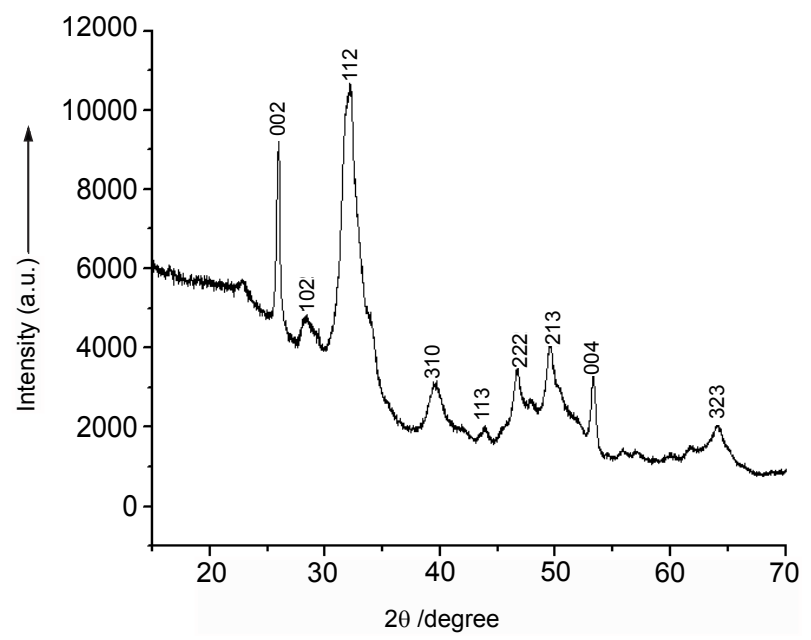

Figure 4: XRD pattern of HAP monolith formed by using $7.5 \mathrm{ml} \mathrm{P}$ (St-MMA$\mathrm{AA})$ (ca. $380 \mathrm{~nm}$ in diameter) colloidal sphere array as template.

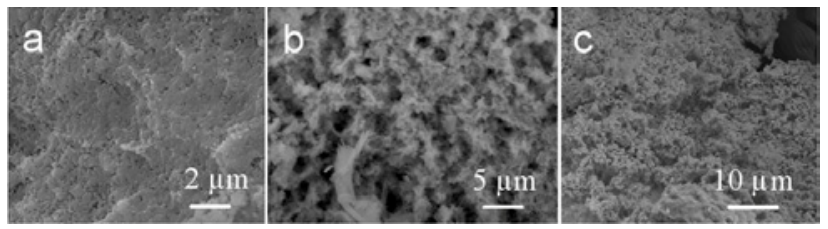

Figure 5: SEM images of HAP monoliths formed by using P (St-MMA-AA) (ca $380 \mathrm{~nm}$ in diameter) colloidal solution with different volume as templates. (a) $3.5 \mathrm{ml}$; (b) $5 \mathrm{ml}$; (c) $7.5 \mathrm{ml}$.
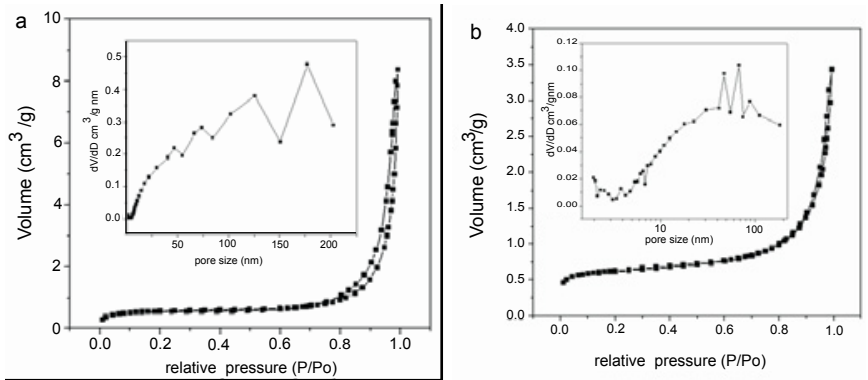

Figure 6: Nitrogen adsorption-desorption isotherm and BJH pore size distribution (inset) of HAP samples obtained under different reaction systems. (a) $2 \mathrm{ml} \mathrm{P}$ (St-MMA-AA) (ca. $170 \mathrm{~nm}$ in diameter), (b) $7.5 \mathrm{ml} \mathrm{P}$ (St-MMA-AA) colloidal solution (ca. $380 \mathrm{~nm}$ in diameter).

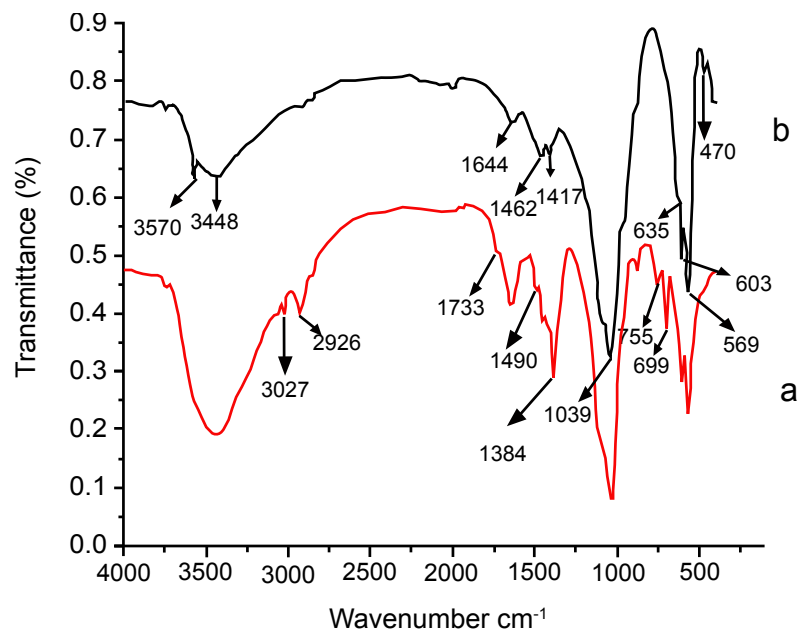

Figure 7: FTIR spectra of HAP samples (a) before and (b) after removal of the polymer colloidal microsphere array.

$\mathrm{C}=\mathrm{C}$ stretching mode of benzenoid rings, the stronger absorption at $2926 \mathrm{~cm}^{-1}$ represents the stretching vibration of $-\mathrm{CH}_{2}$, the characteristic peaks at $~ 1733$ and $699 \mathrm{~cm}^{-1}$ correspond to the $\mathrm{C}=\mathrm{O}$ stretching of PMMA and the out-of-plane bending modes of the benzene ring, respectively. The broad adsorption band at $3445 \mathrm{~cm}^{-1}$ was attributed to the stretching vibration mode of $\mathrm{OH}^{-}$group. The band centered at 1032 $\mathrm{cm}^{-1}$ was characterized the stretching mode of phosphate $\left(\mathrm{PO}_{4}^{3-}, \mathrm{P}-\mathrm{O}\right)$, while the bands at 603 and $564 \mathrm{~cm}^{-1}$ were attributed to the bending mode of phosphate $\left(\mathrm{PO}_{4}^{3-}, \mathrm{O}-\mathrm{P}-\mathrm{O}\right)$. Those are the major characteristic bands of P (St-MMA-AA) and HAP. Nevertheless, in Figure 7b, the bands centered at 1490,2926, 1733 and $699 \mathrm{~cm}^{-1}$ were disappeared, herein, the bands at 1039, 603 and $569 \mathrm{~cm}^{-1}$ were corresponding to the stretching modes of phosphate $\left(\mathrm{PO}_{4}^{3-}, \mathrm{P}-\mathrm{O}\right)$ and the bending mode of phosphate $\left(\mathrm{PO}_{4}^{3-}, \mathrm{O}-\mathrm{P}-\mathrm{O}\right)$. Results indicated that the complete removal of the polymeric species after calcinations and dissolve processing.

Thermo gravimetric analysis (TGA) was employed to examine the weight loss percentage for the as-obtained HAP samples, result was shown in Figure 8, three-stage decomposition was observed for the obtained HAP composite in Figure 8. The first weight-loss region in the first temperature range (ca. $40 \sim 150^{\circ} \mathrm{C}$ ), HAP exhibits a weight loss of $\sim 5 \mathrm{wt}$. \%, the first weight loss stage could be caused by the release of incorporated water; the second weight loss region (ca. $150 \sim 320^{\circ} \mathrm{C}$ ) is likely caused by the initial decomposition for the polymeric colloidal particles, and the P (St-MMA-AA) polymeric was completely burned 
off at around $545^{\circ} \mathrm{C}$, herein, the weight percentage of polymeric in the HAP films is measured to be around 28 wt. \%. As shown in Figure 4, the HAP sample is pure hexagonal structural phase, and no additional peaks for other phases were detected, indicating the completely removal of polymeric latex particles.

\section{Evaluation the bioactivity of HAP monoliths in SBF}

On the other hand, Figure 9 shows $\mathrm{Ca}$ and $\mathrm{P}$ ion concentrations variation among the HAP monoliths in SBF solution for different soaking intervals. The $\mathrm{Ca}$ and $\mathrm{P}$ ion concentrations decrease dramatically during the 126 and $96 \mathrm{~h}$ immersion period, respectively, and then increase slightly. Clearly, the $\mathrm{Ca}$ and $\mathrm{P}$ concentrations variation in SBF throughout the different immersion intervals may be considered as one of the evaluating parameters for in vitro bioactivity of the obtained HAP materials. According to Kokubo theory, in vitro bioactivity of HAP biomaterial could be evaluated by examining the formation ability of apatite crystal on their surface in SBF [35]. Additionally, HAP monoliths with high specific surface area and specific porous features can be readily accelerate the kinetic deposition of the apatite on the coating surface, and also can significantly enhance the bone-forming bioactivity $[36,37]$. The formation of apatite on the surface of HAP in SBF was confirmed by XRD and SEM results, results are shown in Figure 10. The XRD pattern (Figure 10a) of the as-obtained sample after immersion in SBF solution for 5 days shows that the apatite crystals can be formed, the different crystal facets, such as (2212), (0210) and (113), can be easily indexed to the characteristic diffraction peaks of the apatite phase according to JCPDS card no. 09-0169. Furthermore, the SEM images obviously reveal the formation of apatite on the surface of HAP

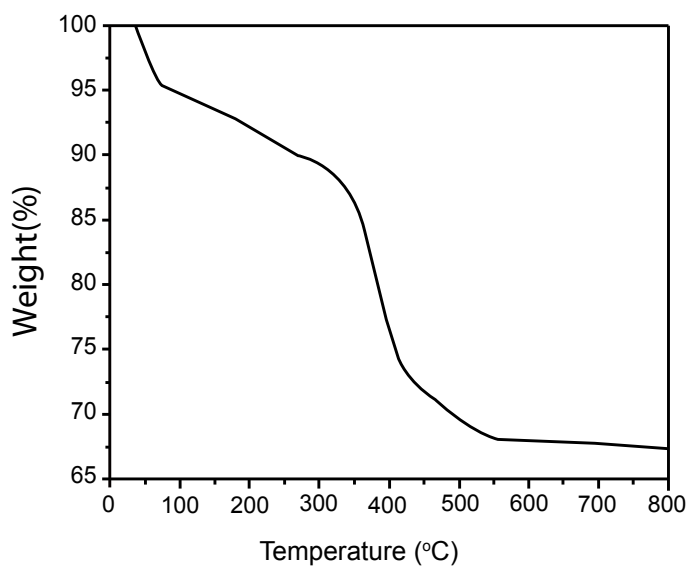

Figure 8: Thermo gravimetric analysis curve of the formed HAP monolith.
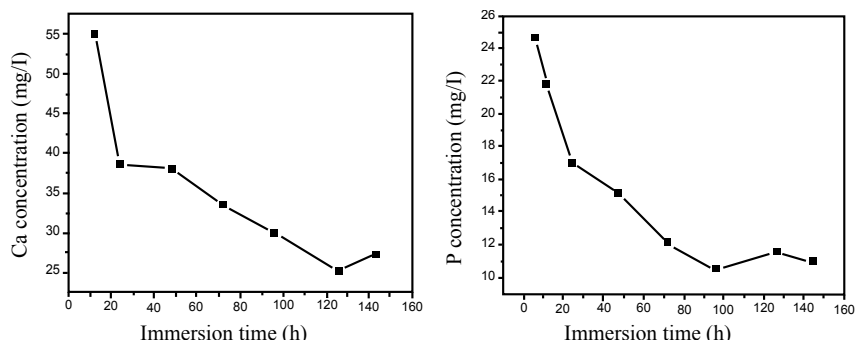

Figure 9: The bioactivity measurement for the prepared HAP monoliths using $2 \mathrm{ml}$ polymer colloidal P (St-MMA-AA) (ca. $170 \mathrm{~nm}$ in diameter) microsphere array as pre-organized template.

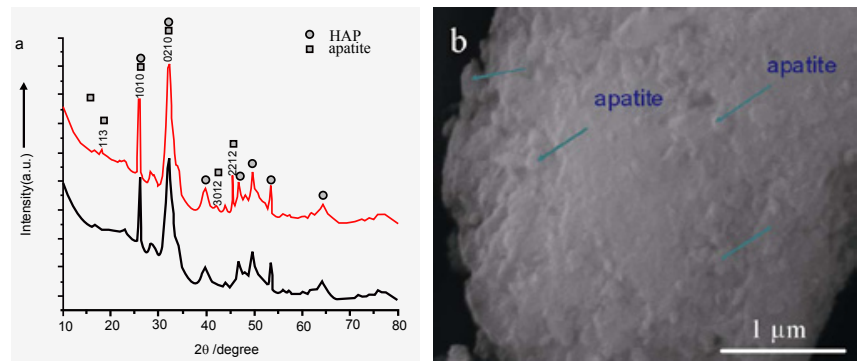

Figure 10: (a) XRD patterns of HAP monolith before (black line) and after (red line) immersed in SBF; (b) SEM image of apatite formed on the HAP monolith surface through immersion in SBF for 5 days at $37^{\circ} \mathrm{C}$

monolith, as shown in Figure 10b. After soaking for 5 days, bone-like apatite crystals were deposited on the surface of the HAP monoliths, it was clearly seen that thicker apatite layer can be formed on the surface of the prepared HAP.

Samples, as indicated by arrows in Figure $10 \mathrm{~b}$. Notably, because the HAP monoliths have larger specific surface area and adjustable surface textures, so, most calcium ions and phosphates ions are easily attached onto their surface and render them to enter the inner layer of porous films. The pores can be acted as ion-transfer channels and therefore play an important role in the formation of bone-like apatite crystals. Therefore, porous HAP monolith materials with higher specific surface area behave superior ability to promote the formation of bone-like apatite and enhanced bioactivity in SBF.

\section{Removal of aqueous $\mathrm{Pb}^{2+}$ and $\mathrm{Cd}^{2+}$}

To investigate the adsorption capacity of the as-obtained HAP monoliths, toxic metal ions, such as $\mathrm{Pb}^{2+}, \mathrm{Cd}^{2+}$ ions in aqueous solution were employed. HAP displays better adsorption performance for waste-water treatment due to its enhanced efficiency for the removal of $\mathrm{Cd}^{2+}, \mathrm{Pb}^{2+}$ and $\mathrm{As}^{2+}$ in a wide range of $\mathrm{pH}(6<\mathrm{pH}<9)$ [38] Currently, four possible immobilization routines, including ion exchange process, surface complexation, dissolution-precipitation, and co-precipitation were generally proposed for the heavy metals adsorption mechanism of the porous HAP materials [39]. Figure 11 shows the bulk-phase lead and cadmium ions concentration attenuation curves when $0.015 \mathrm{~g}$ of the as-prepared HAP sample was added to $25 \mathrm{ml}$ including $\mathrm{Pb}^{2+}$ and $\mathrm{Cd}^{2+}$ solution at room temperature. It is interesting to point out that the adsorption balance could be established in a short time of less than $10 \mathrm{~min}$ for removal of $\mathrm{Pb}^{2+}\left(\left[\mathrm{Pb}^{2+}\right]=200 \mathrm{mg} / \mathrm{l},[\mathrm{HAP}]=0.6 \mathrm{mg} / \mathrm{ml}\right)$, as shown in Figure $11 \mathrm{a}$, almost all the lead ion $\left(\mathrm{Pb}^{2+}\right)$ could be captured within the initial 10 min period. So we can conclude that the $\mathrm{Pb}^{2+}$ adsorption rate of HAP monoliths was rather fast. However, in the case of cadmium $\left(\mathrm{Cd}^{2+}\right)$, it was observed that under the same experiment conditions, the adsorption rate is much slower and capturing c.a. $40 \%$ of $\mathrm{Cd}^{2+}$ from the polluted wastewater after $180 \mathrm{~min}$ immersion interval (Figure 11b). The maximum adsorption amounts for $\mathrm{Pb}^{2+}$ and $\mathrm{Cd}^{2+}$ in aqueous solution are 1.6 and $1.186 \mathrm{mmol} / \mathrm{g}$, respectively, Compared to the reported results in previous literatures, [40] the maximum adsorption amounts of $\mathrm{Pb}^{2+}$ and $\mathrm{Cd}^{2+}$ in solution are 1.17 and 0.57 $\mathrm{mmol} / \mathrm{g}$, respectively; this suggests that $3 \mathrm{D}$ porous HAP monoliths display significantly improved immobilizing efficiency compared to that of the normal HAP materials.

Specially, it is clearly found from Figure 11c that the adsorption rate behaves very different. Probably, the different removal efficiency for $\mathrm{Pb}^{2+}$ and $\mathrm{Cd}^{2+}$ maybe basically resulted from the $\mathrm{pH}$ difference in HAP solution. Clearly, the $\mathrm{Pb}^{2+}$ immobilization is more facilitated 
Citation: Guo XH, Wang WN, Wang MJ, Mao CC, Zhang J, et al. (2012) Facile Fabrication of Porous Hydroxyapatite Monoliths: Their Enhanced Bioactivity and Adsorption Capability for Heavy Metal Ions. J Nanomedic Nanotechnol 3:130. doi:10.4172/2157-7439.1000130

Page 6 of 8

than that of $\mathrm{Cd}^{2+}$ in acid conditions [37]. According to previous study, it was inferred that the dissolution-precipitation mechanism can be responsible for the highly adsorption of $\mathrm{Pb}^{2+}$, moreover, surface complexation and ion-exchange mechanism could dominate the $\mathrm{Cd}^{2+}$ adsorption [40]. Additionally, we examine the $\mathrm{pH}$ value variation in solution, $\mathrm{pH}$ value declined slightly during the $\mathrm{Cd}^{2+}$ adsorption process, while obvious increase of $\mathrm{pH}$ was observed during the $\mathrm{Pb}^{2+}$ adsorption process, as shown in Figure 12. In acid conditions, synthetic hydroxyapatite can easily dissolves and consequently release phosphate that finally lead to the increase of $\mathrm{pH}$ in solution.
In this study, to further validate the proposed adsorption mechanism, XRD and SEM analysis were performed, as shown in Figure 13. In order to study the phase transition of HAP, XRD pattern for HAP samples was displayed in Figure 13a, XRD pattern of HAP after adsorption of $\mathrm{Pb}^{2+}$ shows that a new phase hydroxypyromorphite, $\left[\mathrm{Pb}_{10}\left(\mathrm{PO}_{4}\right)_{6}(\mathrm{OH})_{2}\right]$ could be obtained, and also, the characteristic diffraction peaks of $\mathrm{Cd}_{10}\left(\mathrm{PO}_{4}\right)_{6}(\mathrm{OH})_{2}$ was not observed after immersed in solution containing $\mathrm{Cd}^{2+}$, the XRD patterns of the sample before and after adsorption of $\mathrm{Cd}^{2+}$ are the same, which reveal $\mathrm{Ca}^{2+}$ was completely replaced by $\mathrm{Pb}^{2+}$, Because HAP matrix is of very small size, intra-particle diffusion could take place during the adsorption process, thus HAP
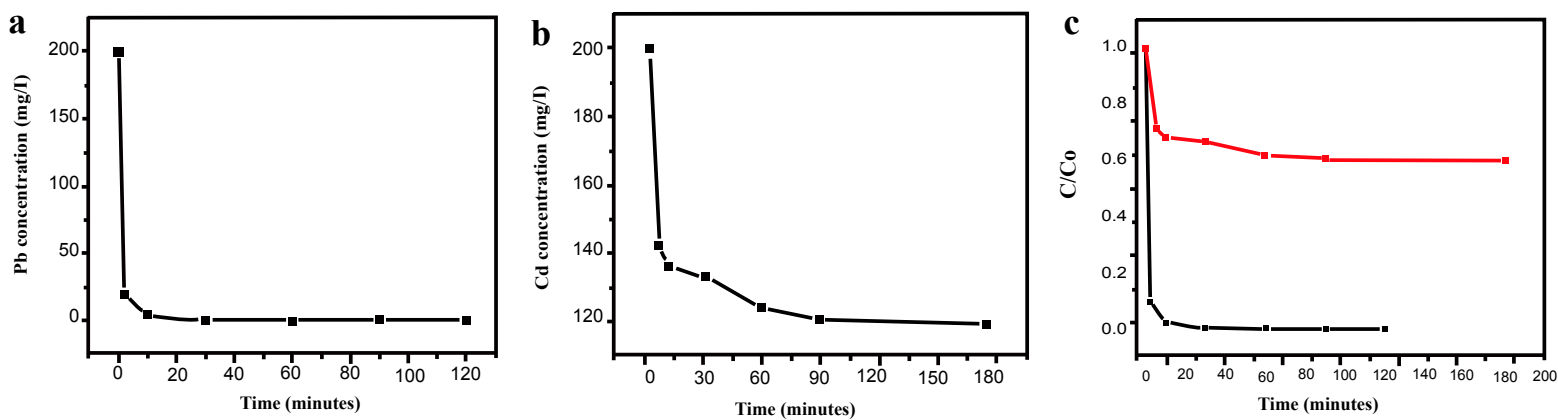

Figure 11: The metal ion adsorption measurement of the prepared HAP samples at different reaction intervals, (a) $\mathrm{Pb}^{2+} \cdot(\mathrm{b}) \mathrm{Cd}^{2+\cdot}$ (c) adsorption rate curves of $\mathrm{Pb}^{2+}$ (black line) and $\mathrm{Cd}^{2+}$ (red line) by the as-prepared HAP monoliths. Co represents the initial concentration (200 mg/l); $\mathrm{C}$ represents the final concentration after adsorption measurement.
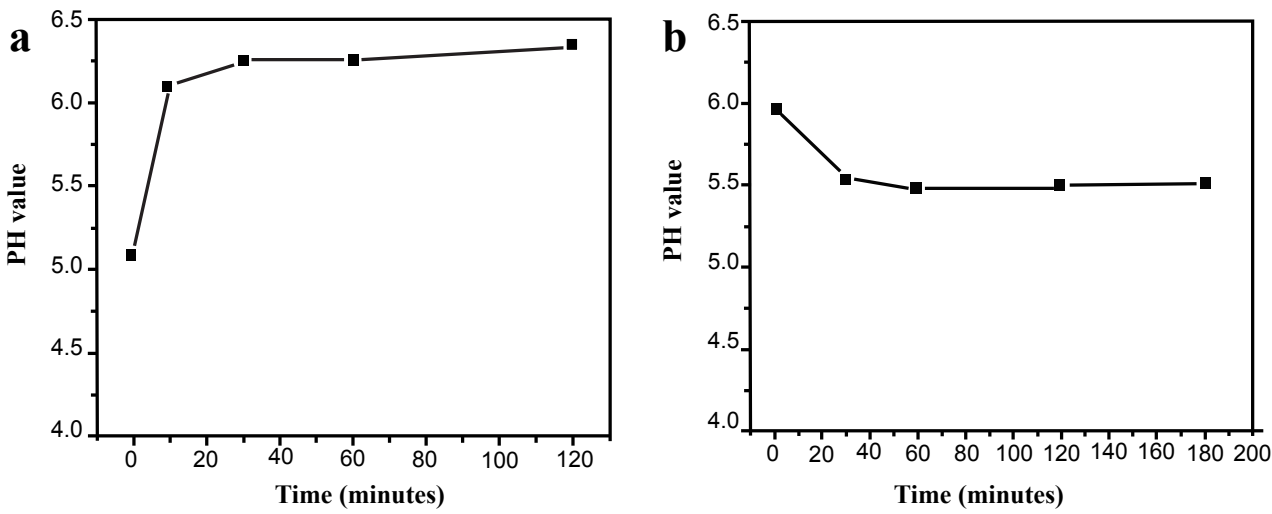

Figure 12: The curves of $\mathrm{pH}$ value variation in aqueous solution after removing lead and cadmium ions via different soaking intervals. (a) $\mathrm{Pb}^{2+}$; (b) $\mathrm{Cd}^{2+}$.
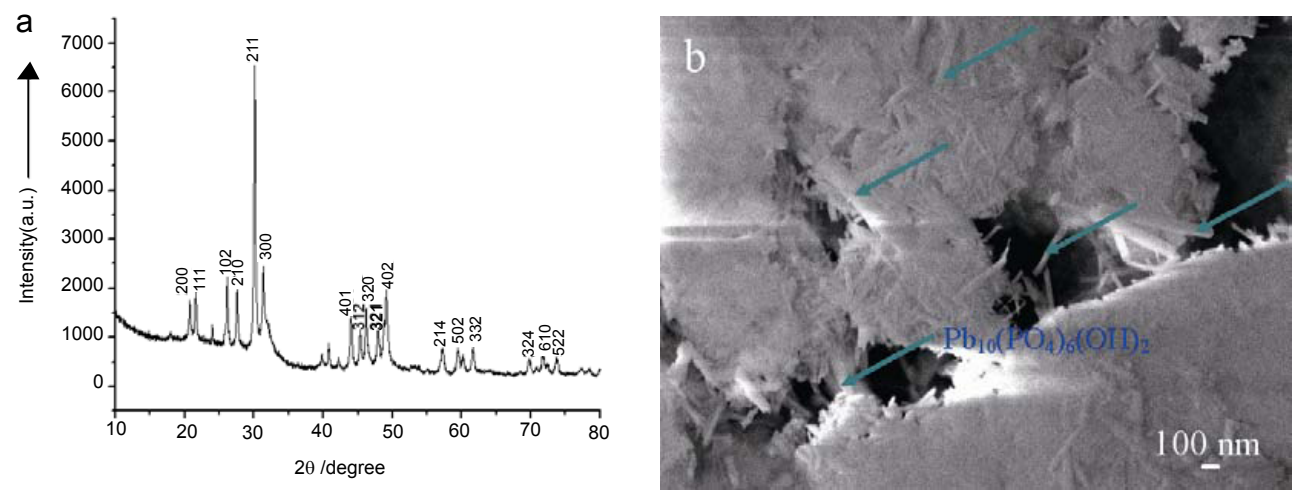

Figure 13: XRD pattern and SEM image of HAP monolith after adsorption lead ions. (a) XRD; (b) SEM. 
Citation: Guo XH, Wang WN, Wang MJ, Mao CC, Zhang J, et al. (2012) Facile Fabrication of Porous Hydroxyapatite Monoliths: Their Enhanced Bioactivity and Adsorption Capability for Heavy Metal lons. J Nanomedic Nanotechnol 3:130. doi:10.4172/2157-7439.1000130

Page 7 of 8

samples can easily dissolves in acid conditions or fast replace by other ions. More importantly, it was speculated that a partial-dissolution of $\mathrm{HAP}$ and re-precipitation mechanism can explain the $\mathrm{Pb}^{2+}$ adsorption case, surface complexation and ion-exchange mechanism can account for the $\mathrm{Cd}^{2+}$ adsorption. Notably, the SEM image (Figure $13 \mathrm{~b}$ ) shows that novel needle-like crystals can be formed after adsorption lead ions in HAP solution, as indicated by arrows in Figure 13 b. But, it was found that there was no presence of HAP crystal, which is well agreed with the $\mathrm{XRD}$ result in Figure 13 a. In this work, the poor crystalline nature means that the HAP monoliths can be easily dissolve in acid aqueous solution, the dissolution-precipitation mechanism predominates the adsorption of $\mathrm{Pb}^{2+}$ in HAP solution; at the same time, it was inferred that surface complexation and ion-exchange mechanism can be responsible for the $\mathrm{Cd}^{2+}$ adsorption in HAP solution.

\section{Conclusions}

In summary, we have demonstrated a simple casting approach to fabricate hierarchically porous HAP monoliths via employing the polymeric colloidal spheres arrays as preorganized templates under mild conditions. HAP monoliths with adjustable morphologies and surface porous features can be obtained by altering the volume of the colloidal solution and the diameter of the polymeric spheres. The asprepared HAP monoliths have hierarchically porous surface textures. Furthermore, the HAP monoliths exhibit greatly enhanced in vitro bone-forming bioactivity in SBF solution; bone-like apatite can be readily formed on the HAP monoliths surface in SBF, which is ascribed to the hierarchically surface textures and the higher specific surface area. Moreover, this kind of HAP monolith showed powerful capability for fast removal of toxic heavy metal ions such as removal of $\mathrm{Pb}^{2+}$ is less than $10 \mathrm{~min}$; on the other side, it showed enhanced immobilizing capacity for $\mathrm{Cd}^{2+}$ than that of normal HAP materials (the maximum adsorption amounts for $\mathrm{Cd}^{2+}$ is $1.186 \mathrm{mmol} / \mathrm{g}$ ). Importantly, the presented synthetic technique can presumably be facilitated to produce other hierarchically inorganic/organic functional monoliths with specific morphologies and architectures.

\section{Acknowledgments}

X. H. Guo specially thanks the funding support from the National Science Foundation Committee of China (NSFC) (No.21001087, 21173167), the Education committee of Shannxi Province (Grant No.2010JK870, 2010JS115).

\section{References}

1. Murugan R, Ramakrishna (2006) Production of ultra-fine bioresorbable carbonated hydroxyapatite. Acta Biomater 2: 201-206.

2. Hench L, Wilson J (1984) Surface-active biomaterials. Science 226: 630-636.

3. Rauschmann M, Wichelhaus TA, Stirnal V, Dingeldein E, Zichner L, et al (2005) Nanocrystalline hydroxyapatite and calcium sulphate as biodegradable composite carrier material for local delivery of antibiotics in bone infections. Biomater 26: 2677-2684

4. Wahl DA, Czernuszka J (2006) Collagen-hydroxyapatite composites for hard tissue repair. Eur Cell Mater 11: 43-56.

5. Dorozhkin SV (2007) Calcium orthophosphates. J Mater Sci 42: 1061-1095.

6. Itokazu M, Yang W, Aoki T, Ohara A, Kato N (1998) Synthesis of antibioticloaded interporous hydroxyapatite blocks by vacuum method and in vitro drug release testing. Biomater 19: 817-819.

7. Almirall A, Larrecq G, Delgado JA (2004) Fabrication of low temperature macroporous hydroxyapatite scaffolds by foaming and hydrolysis of an alphaTCP paste. Biomater 17: 3671-3680.

8. Zhang CM, Li CX, Huang SS, Hou ZY, Cheng ZY, et al. (2010) Self-activated luminescent and mesoporous strontium hydroxyapatite nanorods for drug delivery. Biomater 31: 3374-3383.

9. Hou ZY, Yang PP, Lian HZ, Wang L, Zhang CM, et al. (2009) Multifunctional hydroxyapatite nanofibers and microbelts as drug carriers. Chem Eur $\mathrm{J} 15$ 6973-6982.

10. Hui J, Xiang GL, Xu XX, Zhuang J, Wang X (2009) Monodisperse F-substituted hydroxyapatite single-crystal nanotubes with amphiphilic surface properties. Inorg Chem 48: 5614-5616

11. Zhang CM, Cheng ZY, Yang P, Xu ZH, Peng C, et al. (2009) Architectures of strontium hydroxyapatite microspheres: solvothermal synthesis and luminescence properties. Langmuir 25: 13591-13598.

12. Ma M, Zhu JF (2009) Solvothermal Synthesis and Characterization of Hierarchically Nanostructured Hydroxyapatite Hollow Spheres. Eur J Inorg Chem 36: 5522-5526.

13. Yang P, Quan ZW, Li CX, Kang XJ, Lian HZ (2008) Bioactive, luminescent and mesoporous europium-doped hydroxyapatite as a drug carrier. Biomater 29 : 4341-4347.

14. Liu DX, Savino K, Yates MZ (2009) Microstructural engineering of hydroxyapatite membranes to enhance proton conductivity. Adv Func Mater 19: 3941-3947.

15. Xiao JW, Zhu YC, Ruan QC, Liu Y, Zeng Y, et al. (2010) Biomacromolecule and surfactant complex matrix for oriented stack of 2-dimensional carbonated hydroxyapatite nanosheets as alignment in calcified tissues. Crystal Growth Design 10: 1492-1499.

16. Viswanath B, Ravishankar (2008) Controlled synthesis of plate-shaped hydroxyapatite and implications for the morphology of the apatite phase in bone. N Biomater 29: 4855-4863.

17. Guo XH, Wang WN, Zhang J, Mao CC, Deng YH (2011) Controlled synthesis of hydroxyapatite crystals templated by novel surfactants and their enhanced bioactivity. New J Chem 35: 663-670.

18. Vasiliev A N, Zlotnikov E, Khinast J G, Riman R E (2008) Chemisorption of silane compounds on hydroxyapatites of various morphologies. Scripta Mater 58: $1039-1042$

19. Shi QH, Wang JF, Zhang JP, Fan J, Stucky GD (2006) Rapid-Setting, Mesoporous, Bioactive Glass Cements that Induce Accelerated In Vitro Apatite Formation. Adv Mater 18: 1038-1042.

20. Ni SY, Chang J, Chou L (2006) A novel bioactive porous $\mathrm{CaSiO}_{3}$ scaffold for bone tissue engineering. J Biomed Mater Res 76: 196-205.

21. Jun YK, Kim WH, Kweon OK, Hong SH (2003) The fabrication and biochemical evaluation of alumina reinforced calcium phosphate porous implants. Biomaterials 24: 3731-3739.

22. Sepulveda P, Jones JR, Hench LL (2002) Bioactive sol-gel foams for tissue repair. J Biomed Mater Res 59: 340-348.

23. Okii N, Nishimura S, Kurisu K, Takeshima Y, Uozumi T (2001) In vivo histological changes occurring in hydroxyapatite cranial reconstruction--case report. Neurol Med Chir (Tokyo) 41: 100-104.

24. Hench LL (1997) Sol-gel materials for bioceramic applications. Curr Opin Solid State Mater Sci 2: 604-610.

25. Drisko GL, Luca V, Sizgek E, Scales N, Caruso RA (2009) Template synthesis and adsorption properties of hierarchically porous zirconium titanium oxides. Langmuir 25: 5286-5293.

26. Sizgek GD, Sizgek E, Griffith CS, Luca V (2008) Mesoporous zirconium titanium oxides. Part 2: Synthesis, porosity, and adsorption properties of beads. Langmuir 24: 2323-12330.

27. Bao QH, Chen C, Wang DG, Liu JM (2008) Characterization of hydroxyapatite films prepared by pulsed laser deposition. Crystal Growth \& Design 8: 219-223.

28. Büyükaksoy A, Köseoglu NC, Aslan MH, Oral AY (2009) Microstructural study of $\mathrm{Mn}$ and $\mathrm{Si}$ Co-substituted hydroxyapatite thin films produced by a sol-gel method. Adv Engin Mater 11: 77-81.

29. Kimura T, Miyamoto N, Meng X, Ohji T, Kato K (2009) Rapid fabrication of mesoporous titania films with controlled macroporosity to improve photocatalytic property. Chem Asian J 4: 1486-1493.

30. Ryu J, Ku SH, Lee H, Park CB (2010) Mussel-Inspired Polydopamine Coating as a Universal Route to Hydroxyapatite Crystallization. Adv Funct Mater 20: 2132-2139. 
Citation: Guo XH, Wang WN, Wang MJ, Mao CC, Zhang J, et al. (2012) Facile Fabrication of Porous Hydroxyapatite Monoliths: Their Enhanced Bioactivity and Adsorption Capability for Heavy Metal lons. J Nanomedic Nanotechnol 3:130. doi:10.4172/2157-7439.1000130

31. Cui W, Li X, Xie C, Zhuang H, Zhou S, et al. (2010) Hydroxyapatite nucleation and growth mechanism on electrospun fibers functionalized with different chemical groups and their combinations. Biomater 31: 4620-4629.

32. Li C, Qi L (2008) Bioinspired fabrication of 3D ordered macroporous single crystals of calcite from a transient amorphous phase. Angew Chem Int Ed Engl 47: 2388-2393

33. Sakota K, Okaya T (1977) Polymerization behavior and distribution of carboxy groups in preparation of soap-free carboxylated polystyrene latexes. J Appl Polym Sci 21: 1035-1043.

34. Kokubo T, Takadama $\mathrm{H}$ (2006) How useful is SBF in predicting in vivo bone bioactivity. Biomaterials 27:" 2907-2915

35. Yan X, Huang X, Yu C, Deng H, Wang Y, et al. (2006) The in-vitro bioactivity of mesoporous bioactive glasses. Biomater 27: 3796-3403.
36. Yan X, Yu C, Zhou X, Tang J, Zhao D (2004) Highly ordered mesoporous bioactive glasses with superior in vitro bone-forming bioactivities. Angew Chem Int Ed Engl. 43: 5980-5984.

37. Lopez-Noriega A Arcos D, Izquierdo-Barba I, Sakamoto Y, Terasaki O, et al. (2006) Ordered Mesoporous Bioactive Glasses for Bone Tissue Regeneration. Chem Mater 18: 3137-3144.

38. Elouear Z, Bouzid J, Boujelben N, Feki M, Jamoussi F, et al. (2008) Heavy metal removal from aqueous solutions by activated phosphate rock. J Hazard Mater 156: 412-420.

39. Hodson ME, Valsami-Jones E, Cotter-Howells JD (2000) Bonemeal Additions as a Remediation Treatment for Metal Contaminated Soil. Enviro Sci Techn 34: 3501-3507.

40. Zhang Z, Li M, Chen W, Zhu S, Liu N, et al. (2010) Immobilization of lead and cadmium from aqueous solution and contaminated sediment using nanohydroxyapatite. Environ Pollut 158: 514-519. 